Article

\title{
Spatial Analysis of Social Vulnerability to Floods Based on the MOVE Framework and Information Entropy Method: Case Study of Katsushika Ward, Tokyo
}

\author{
Lianxiao $^{1, *}$ and Takehiro Morimoto ${ }^{2}$ \\ 1 Graduate School of Life and Environmental Sciences, University of Tsukuba, 1-1-1 Tennodai, Tsukuba, \\ Ibaraki 305-8572, Japan \\ 2 Faculty of Life and Environmental Sciences, University of Tsukuba, 1-1-1 Tennodai, Tsukuba, \\ Ibaraki 305-8572, Japan; tmrmt@geoenv.tsukuba.ac.jp \\ * Correspondence: s1630228@u.tsukuba.ac.jp
}

Received: 21 November 2018; Accepted: 16 January 2019; Published: 20 January 2019

\begin{abstract}
Tokyo is located in a lowland area that is vulnerable to flooding. Due to global climate change, the scalability and frequency of flooding is increasing. On the other hand, population aging and family structural changes, as well as the lack of adaptation measures, would accelerate flooding vulnerability. The key factors involved in social vulnerability must be studied to reduce the risk of flooding. In this study, we refer to the MOVE framework (a disaster vulnerability assessment framework) and analyze it from three perspectives: Exposure to social vulnerability, susceptibility, and resilience. We subsequently develop an index system to complete the evaluation using 11 indicators. The collected data will help reveal social vulnerability to floods in the Katsushika Ward, Tokyo, using the information entropy method and GIS. We found that the western region of the Katsushika Ward is at more risk than the eastern region during flooding. Additionally, the possibility of a serious crisis erupting is greater in the southwestern region than in the northwestern region. Consequently, we conclude that the spatial distribution of flooding varies in the region. The results of this study will help in understanding social vulnerability, in selecting and combining adaptation measures suited to the characteristics of the area, and in the effective and efficient implementation of these measures by the local government's disaster department.
\end{abstract}

Keywords: flood; MOVE framework; information entropy method; GIS; spatial analysis; social vulnerability

\section{Introduction}

According to the report by the Intergovernmental Panel on Climate Change (IPCC, 2007), low-lying areas, especially in densely populated areas of East and South-East Asia, have a relatively low adaptive capacity and will face a higher risk of flooding due to increased coastal flooding [1]. The report also predicts that by 2100, more people will be flooded each year in these areas due to rising sea levels (IPCC, 2014). The population aging in the region and changes in family structure, as well as the lack of adaptation measures, will reduce people's ability to adapt to such changes and accelerate flood vulnerability [2]. The IPCC's latest 1.5 Degrees report (IPCC, 2018) pointed out that it is necessary to reduce the vulnerability of floods and to accelerate adaptive capacity [3]. Therefore, assessing vulnerability to flooding disasters is an important step in reducing flooding vulnerability and accelerating resilience. In the past, many studies on flooding vulnerability have been carried out, but most studies have not focused on social vulnerability, which is essential to reducing flooding 
vulnerability. Social vulnerability refers to the characteristics of a person or group in terms of their capacity to anticipate, cope with, resist, and recover from the impact of a natural hazard [4]. It is a term used to describe the extent of the vulnerability of a particular social group, organization, or country to damages or losses when encountering a disaster [5]. Social vulnerability is related to gender, class, race, age, and poverty [6-10]. In terms of age, the social vulnerability of the young and the elderly populations is high, because these are the age groups that cannot easily seek refuge on their own during disasters. Women are at a higher risk because the distribution of low-class status and income distribution of women indicate that a large number of elderly women live by themselves. Therefore, their capacity for post-disaster recovery is poor [11]. These social factors influence the distribution of resources and power that are necessary for disaster preparedness and countermeasures. Their requirements will be different, along with the difference in vulnerability $[9,12]$.

A better understanding of the level of vulnerability and how the susceptible population is distributed can be beneficial for better management of disaster risk [13]. In the framework for disaster risk mitigation in Sendai City, it was proposed that the social vulnerability of a disaster should be recognized accurately along with the possibility of a reduction in disaster damages for the most vulnerable areas. The social vulnerability assessment is an important step in building regional robustness against flood risks [14,15], and helps identify and measure local factors of vulnerability $[16,17]$. Research on social vulnerability to disasters has gained attention in recent years $[12,18,19]$.

Social vulnerability indices have emerged as a leading tool to quantify and map the human dimensions of hazards vulnerability [20]. From a set of seminal studies [4,6,21,22], the concept of social vulnerability has been formed. Currently, the field of social vulnerability has not yet formed a special assessment framework $[15,23]$. Social vulnerability assessment frameworks have expanded to address questions of scale [21,24,25], temporal change [26], specific hazards [27-29], integration with ecological environment vulnerability [21], and economic vulnerability [14].

Although the research on the social vulnerability framework is in progress, there are still some problems. In terms of scale, there are relatively more studies on social vulnerability at the national, local government, and urban levels [30-34]. However, there are few studies on regional differences of social vulnerabilities in meso-scales and small-scales $[35,36]$. Therefore, it is necessary to study the social vulnerability at both the meso-scale and the small-scale to implement measures to reduce social vulnerability more accurately and appropriately.

In terms of specific hazards, disasters include small-scale, large-scale, frequent, and rare ones and hazards, etc. However, there are few studies on the social vulnerability to floods at a large-scale when considering setting the worst conditions. It is still difficult to adapt to the future trend of large-scale floods [37]. Therefore, it is necessary to study the social vulnerability to large-scale floods by setting the conditions to reflect the worst case. The social vulnerability index still shows a good consistency to some extent regarding the index construction method. However, such consistency is likely to yield misleading conclusions [20]. To address these issues, it is necessary to include indicators that can reflect local social vulnerability. Furthermore, the social vulnerability indicators include population density, gender discrimination, socioeconomic status, and public health conditions. These are considered to be the most important causes of vulnerability in individuals exposed to disasters and emergencies [38-42]. Owing to changes in natural and socioeconomic environments, the social vulnerability has changed as well. It is, therefore, necessary to include new indicators to reflect local vulnerabilities [34]. As far as the index weighting method is concerned, the subjective valuation method is too subjective, which would reduce the credibility of the social vulnerability assessment [33]. Therefore, in this paper, we use the information entropy weight method as the typical objective assignment method to determine the index weight.

This study aims to improve the evaluation of social vulnerability to large flood hazards in small regions. GIS-based techniques and the information entropy weight method are employed to estimate social vulnerability quantitatively. This study refers to a comprehensive vulnerability 
assessment framework for the evaluation of social vulnerability. Regarding local indicators, this study refines the children's indicators and the elderly indicators and adds some new indicators, such as isolated populations.

The study area is in Tokyo, Japan. Approximately $41 \%$ of the population and approximately $65 \%$ of the assets in Japan are concentrated in its flood prone areas. They constitute approximately $9 \%$ of the national land area, implying that the exposure to flooding is high [43]. Recently, the vulnerability to floods has increased with an aging population, the deterioration of flood control facilities, and the diminishing of the residents' sense of crisis. Additionally, the concentration of population and assets renders the situation worse [4]. It also leads to changes in the social vulnerability of floods. Who is a vulnerable group now? Where are they living? It is important to know the answers to these questions. Once we can reduce social vulnerability and enhance flood prevention ability, we are able to alleviate the damage caused by floods. At present, the Japanese government's measures to reduce social vulnerability are based on rarely targeted areas in the city. However, there are differences in the social factors for each district, so there remain many inappropriate measures taken by the city to reduce social vulnerability. Therefore, it is necessary for us to recognize and assess the social vulnerability by districts [14,44]. Mapping the distribution of a district's social vulnerabilities will be beneficial for local governments to guide the reduction of social vulnerabilities and the establishment of appropriate mitigation plans.

\section{Data and Methods}

\subsection{Study Area}

The study area is Katsushika Ward, located in the northeastern part of Tokyo, east longitude $139^{\circ} 50^{\prime}-139^{\circ} 55^{\prime}$, north latitude $35^{\circ} 41^{\prime}-35^{\circ} 48^{\prime}$ (Figure 1). It has an area of 34.80 square kilometers and a population of 45,294 people. Elevation in the eastern part is less than in the western region. This area is surrounded by the rivers Arakawa and Ayase in the west, Nakagawa and Shinnakagawa in the center, and Edogawa in the east. The climate is warm, and rainfall is constant, even during dry seasons. The average annual rainfall is $1412 \mathrm{~mm}$. This area has suffered from flooding owing to its topography, hydrology, and other factors; 110 floods have occurred since 1742. In recent years, flood vulnerability has been increasing, along with ground subsidence and population aging. The area has not experienced large-scale floods for 70 years, and the residents' awareness of disaster prevention is weak. It is necessary to reduce the degree of exposure and sensitivity to floods, and to focus more on areas with high social vulnerability to floods. 


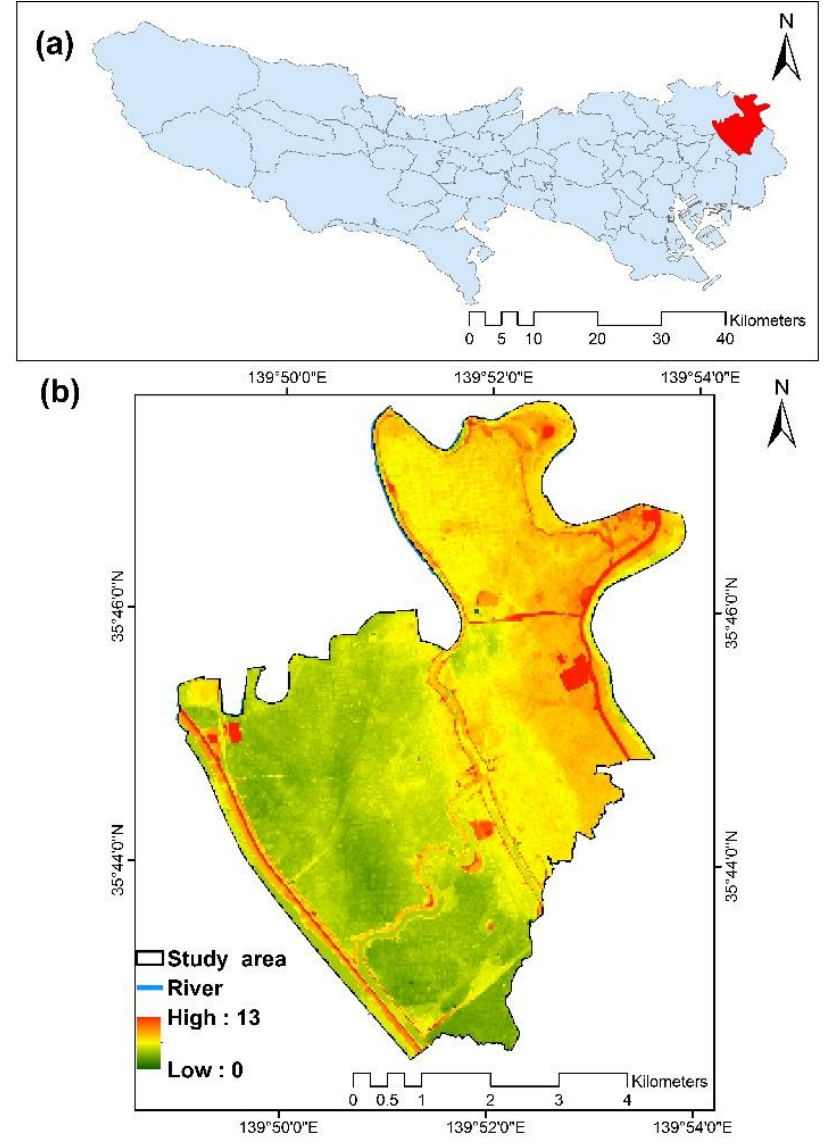

Figure 1. The study area: (a) Tokyo area; (b) Katsushika Ward.

\subsection{MOVE framework}

The MOVE framework (Figure 2) was developed as an assessment framework, arising from the MOVE project, an improvement of the vulnerability assessment method, conducted from 2008-2011 in Europe. The MOVE framework was built with reference to the project on past vulnerabilities in Europe, and the concept of vulnerability and the framework of the vulnerability used worldwide. It analyzes the physical, technical, environmental, social, cultural, and institutional vulnerability to a specific hazard and considers countermeasures for improving social and economic resilience. It is a framework of a multidimensional, comprehensive, systematic vulnerability assessment [45-47]. It has been reported that the social vulnerability of a group depends on its degree of exposure, sensitivity, and capability to respond to dangerous situations [17,26,47]. A primary outcome of the project is the implementation of the MOVE web-based indicator database (MOVE wb-db), which supports the transformation of research results into a suitable format for analysis. To improve the MOVE project, all partners involved in MOVE wb-db invited participants worldwide to contribute their knowledge for the improvement of the two methodologies used in Europe and those that can be applied worldwide. The MOVE wb-db collects the indicators to assess vulnerability used in Barcelona, Cologne/Bonn, London, North-Western Portugal, Prato, Pistoia, Florence Lucca, Salzach River, and South Tyrol, the seven case study areas involved in the project [7]. Birkmann (2013) and Borg et al. (2014) conducted their research based on this framework $[7,26]$.

The MOVE framework is a method used to assess social vulnerability because its indexing can be adapted and scaled. These advantages enable the incorporation of local vulnerability-related indicators to render disaster prevention strategies more suitable for local conditions. Thus, the MOVE framework better fits the study objectives.

We used the MOVE framework in this study to evaluate the social vulnerability to floods, using the index sections of the degree of exposure, susceptibility, resilience, and the situation analyzed 
specific to its region (Table 1). Based on the MOVE framework, Depietri (2013) used GIS to analyze the vulnerability of Cologne's urban population to heat waves [47]. Additionally, Hagenlocher (2013) used GIS to assess the socioeconomic vulnerability of dengue fever to 340 communities in Cali's core urban area in Colombia [48]. Referring to the MOVE framework, the vulnerability of farmers to flood disasters in Nigeria was analyzed using questionnaires, expert interviews, and GIS. Bizimana (2015) analyzed the social vulnerability of groups in Rwanda to malaria using a composite index method and GIS [49], and Williams (2018) used the MOVE framework with GIS to analyze the social vulnerability of Nigeria's Katsina-Ala local government area to malaria. The results of these studies confirm that the MOVE framework is reasonable [50].

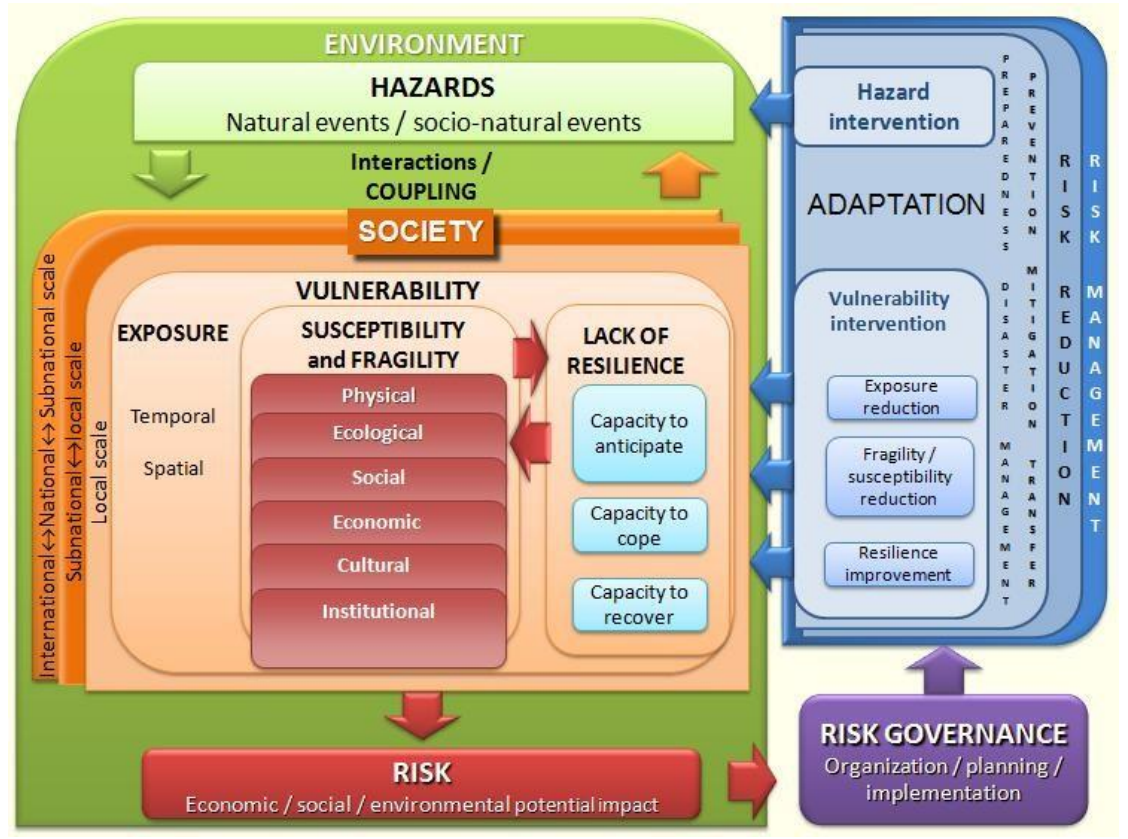

Figure 2. The MOVE Framework (Source: Birkmann, 2013 [26]).

Table 1. Explanation of indicators.

\begin{tabular}{|c|c|c|c|}
\hline Evaluation Item & Index & Description & Nature \\
\hline \multirow{3}{*}{ Exposure } & population (number) & $\begin{array}{l}\text { The greater the population, the higher is the } \\
\text { degree of exposure [17] }\end{array}$ & + \\
\hline & Submersion depth (m) & $\begin{array}{l}\text { The deeper the flood depth, the higher is } \\
\text { the degree of population exposure [51] }\end{array}$ & + \\
\hline & Submersion time $(\mathrm{h})$ & $\begin{array}{l}\text { The longer the submersion time, the higher } \\
\text { the degree of population exposure [2] }\end{array}$ & + \\
\hline \multirow{5}{*}{ Susceptibility } & $\begin{array}{l}0-9 \text { years old population } \\
\text { (number) }\end{array}$ & Children cannot evacuate on their own [17] & + \\
\hline & $\begin{array}{l}\text { 65-74 years old population } \\
\text { (number) }\end{array}$ & Cannot evacuate on their own [2] & + \\
\hline & $\begin{array}{l}\text { Over } 75 \text { years old } \\
\text { population (number) }\end{array}$ & $\begin{array}{c}\text { Cannot evacuate independently, the degree } \\
\text { of necessary care is high [2] }\end{array}$ & + \\
\hline & $\begin{array}{l}\text { Female population } \\
\text { (number) }\end{array}$ & $\begin{array}{c}\text { The higher the population is, the higher the } \\
\text { sensitivity }[40,41]\end{array}$ & + \\
\hline & $\begin{array}{l}\text { the isolated population } \\
\text { (number) }\end{array}$ & $\begin{array}{l}\text { The higher the population is, the higher the } \\
\text { sensitivity [2] }\end{array}$ & + \\
\hline \multirow{3}{*}{ Resilience } & $\begin{array}{c}\text { Density of medical } \\
\text { facilities (number } / \mathrm{m}^{2} \text { ) }\end{array}$ & $\begin{array}{l}\text { The higher the density is, the higher the } \\
\text { capacity [17] }\end{array}$ & - \\
\hline & $\begin{array}{l}\text { Family personnel } \\
\text { (number) }\end{array}$ & $\begin{array}{l}\text { The more people in the family, the higher } \\
\text { the ability to respond [40] }\end{array}$ & - \\
\hline & $\begin{array}{l}\text { Density of evacuation } \\
\text { facility (number } / \mathrm{m}^{2} \text { ) }\end{array}$ & $\begin{array}{l}\text { The higher the density is, the higher the } \\
\text { response capability [17] }\end{array}$ & - \\
\hline
\end{tabular}

Notes: (“+” = increasing vulnerability, "-" = decreasing vulnerability). 


\subsection{Data Collection and Processing}

\subsubsection{Data Used for Research}

The data regarding submersion depth and submergence time were provided by the Arakawa upstream river office of the Kanto Regional Development Bureau, Ministry of Land, Infrastructure and Transport. These data are arranged in a $25 \mathrm{~m} \times 25 \mathrm{~m}$ grid. The data were collated in 2016, and were based on the assumption that the embankment of the river in the Arakawa Downstream Region could collapse owing to the approximate total rainfall of $632 \mathrm{~mm}$ in $72 \mathrm{~h}$. The probability of this situation occurring is estimated as once every 200 years. A large-scale flood in the Katsushika area occurred in 1742 and another large-scale flood occurred in 1947.

The population data are the residential nighttime population data from the 2010 National Population Census. They were downloaded from the e-Stat website of the Ministry of Internal Affairs and Communications. The $250 \times 250 \mathrm{~m}$ grid population data and small regional population data were used in this study. ArcGIS10.4 of ESRI (Tokyo, Japan) was used to obtain the population data of age groups representing 0-9 years old, 65-74 years old, and over 75 years old. The number of households based on the population data was proportionally divided by the area rate [52]. The data for medical and evacuation facilities were downloaded from the National Land Numeral Information Website. These data were in shapefile format. The densities of the medical and evacuation facilities were calculated in the ArcGIS. By means of ArcGIS, we were able to combine the data regarding submersion depth and submergence time with that described above to obtain the data used in this study.

\subsubsection{Selection of Indicators}

Referring to the MOVE framework, an indicator system for assessing the social vulnerability to floods was constructed in this work. We subsequently used the information entropy method and GIS to elucidate the spatial distribution of the social vulnerability to flooding in the study area.

The degree of exposure entails the situation of peoples, infrastructure, housing, production capacities, and other tangible human assets located in hazard-prone areas [53]. An increase in the submersion depth and submersion time also increases the area and population exposed to floods, thus increasing the vulnerability. The higher the population of a particular area, the higher its exposure and vulnerability. In addition, the submersion depth, the submersion time, and the population were used as indicators of the degree and scale of exposure.

"Sensitivity" refers to the susceptibility of a population; that is, its damage risk when flooding occurs [26]. The degree of susceptibility varies according to the age, sex, and health condition of the population. Many studies indicate that children, elderly people, and women are highly susceptible $[15,54]$. It is very difficult for children to seek refuge because of their insufficient physical strength and insufficient understanding of the situation. Hence, the probability of infection after a disaster is high. The average height of a 9-year-old male in Japan is $1.35 \mathrm{~m}$, and the threshold for walking refuge is $70 \mathrm{~cm}$; hence, it is difficult for a child to obtain shelter on their own during a flood. Kablan (2017) analyzed society's vulnerability to flooding. The research used the number of children under the age of 5 as a kid indicator. The 5-9 years old population was left out of the kid indicator in flooding [17]. Therefore, children under the age of 9 were chosen for this study.

The elderly cannot seek refuge easily owing to their insufficient physical strength and ability to receive information in the case of disaster warnings. Miwa (2013) analyzed society's vulnerability to fire disaster. The research used the 65-74 years old population and over 75 years old population as elderly indicators. The ability of the elderly to seek refuge varies among these age ranges [2]. Owing to their low socioeconomic status, the distribution of resources and rights to women in times of disaster is uneven. The sensitivity indicators for natural disasters in Japan are changing according to the broader climatological and socioeconomic developments [2,44]. An isolated population value from 2008 was used in this study for disaster mitigation measures. When the depth of submersion and submersion time reach certain values, facility functions, such as water supply, sewerage, electricity, 
and gas, in many areas are stopped, and drinking water and food in refrigerators cannot be used for a long time; therefore, scarcity cases exist where people are isolated in floods. Water and other relief supplies are scarce in isolated areas. If the isolation continues, it will cause casualties. Hence, the categories 0-9 years old, 65-74 years old, over 75 years old, the female population, and the isolated population were used for the index of susceptibility.

Resilience (R) is the ability of a system, community, or society exposed to hazards to resist, absorb, accommodate, adapt to, transform, and recover from the effects of a hazard in a timely and efficient manner, including through the preservation and restoration of its essential basic structures and functions through risk management [53]. During the flooding incident, a timely evacuation can reflect the response capacity of the residents. Families with many members are more likely to receive early warnings of an oncoming disaster, which in turn implies that they have a greater chance at evacuation. Refuge facilities reflect the ability of resistance to floods. The density of medical facilities can reflect the ability to recover from flood disasters. Places with many medical facilities have a higher ability to prevent infections and other diseases caused by floods. Resilience is related to medical services, social networks, physical security, preparations for disasters, and early alarm [8]. In the analysis of this study, the densities of medical and evacuation facilities, and the average number of people per household were used as indicators of resilience.

\subsubsection{Standardization}

Data standardization is a typical data conversion measure in data mining that scales data to a small specific interval [55]. Data standardization can be converted to a dimensionless value that allows for different units or magnitudes of indicators to be compared and weighted. In this study, the units of the evaluation indicators are different; therefore, using the most typical min-max normalization method, which is a linear transformation of the original data, the results can be obtained in the $[0,1]$ interval, and the conversion functions are described as follows.

Processing of positive indicators:

$$
x_{i j}^{\prime}=\left(x_{i j}-\min x_{i j}\right) /\left(\max x_{i j}-\min x_{i j}\right),
$$

Processing of negative indicators:

$$
x_{i j}^{\prime}=\left(\max x_{i j}-x_{i j}\right) /\left(\max x_{i j}-\min x_{i j}\right),
$$

Among them, $x_{i j}$ is the original value of the $\mathrm{j}$-th index of the $i$-th evaluation item, and $x_{i j}^{\prime}$ is a standardized value of that value. $\max x_{i j}$ is the maximum value of the $j$-th index and $\min x_{i j}$ is the minimum value of the $j$-th index.

\subsection{Information Entropy Method}

In project evaluation and multi-objective decision making, it is generally necessary to assign a weight to each evaluation indicator to determine its relative importance. Currently, subjective and objective weighing methods are used to determine the weights. Information entropy was proposed by Shannonn of Bell Labs in the United States in 1948, which reflects the degree of information disorder and is generally used to determine the objective weights [56]. A greater degree of variation in terms of the indicator value will result in a smaller information entropy of the obtained index. This could be critical in a comprehensive evaluation. The disadvantage of not having such information is that the influence of subjective factors is significant. On the contrary, a smaller degree of variation in the indicator value results in larger information entropy; this is less influential in a comprehensive evaluation, and the weight becomes smaller. Therefore, using the information entropy to evaluate the obtained weights can avoid the interference of subjective factors, and render the evaluation results more realistic [57]. Currently, it has been widely used in engineering, social, and economic fields. 
The specific gravity, $P_{i j}$, among $\mathrm{m}$ indices of the $i$-th evaluation item of the index, $j$, is as follows:

$$
P_{i j}=x_{i j}^{\prime} / \sum_{i=1}^{m} x_{i j}^{\prime}
$$

Among them, $x_{i j}^{\prime}$ is a standardized value of that value.

Calculation of information entropy, $\mathrm{E}_{j}$, of index $j$ :

$$
\mathrm{E}_{j}=-\mathrm{K} \sum_{i=1}^{m} P_{i j} \ln P_{i j}
$$

In which, $\mathrm{K}=1 / \ln m$, assured when $P_{i j}=0, P_{i j} \ln P_{i j}=0$.

Calculation of the utility value, $D_{j}$, of index $j$ :

$$
D_{j}=1-\mathrm{E}_{j}
$$

In which, the larger the value of $\mathrm{E}_{j}$, the smaller value of $D_{j}$ is obtained.

Calculation of weight, $w_{j}$, of index $j$ :

$$
w_{j}=D_{j} / \sum D_{j}
$$

In which, the smaller the information entropy of an indicator, the greater weight in the comprehensive evaluation.

\subsection{Calculation of the Social Vulnerability of Floods}

In 1989, Feldt and Brennan proposed the "weighted composites," a method of calculating the composite score using a combination of the exponential score and the product of its weights [58]. It can be used to study the reliability of composite scores within the MOVE framework. Currently, it is widely used in various evaluation studies based on indicators to calculate the total value of a certain evaluation item. For many studies, the value of the evaluation item is calculated using the following formula $[17,45]$ :

$$
y=\sum_{i=1}^{m} w_{i} x \prime_{i}
$$

where $y$ is the value of the item that evaluates the social vulnerability, where $m$ is the number of indicators used in this study, $x I_{i}$ is the standardized value of the $i$-th indicator in the m index, and $w_{i}$ is the weight of this index.

To analyze the origins and after effects of disasters, we discovered insufficient uniform information as well as uniform methods of analysis for calculating social vulnerability. Based on the sum of relevant vulnerability indices, Ge (2005) considered the disaster loss and the relevant attributes of disaster-causing factors to obtain the social vulnerability [31]. Wang (2018) used the sum of the three evaluation projects to derive the overall social vulnerability [36]. Because of the different social vulnerability assessment projects, the calculation methods and results were different. Depietri (2013) and Kablan (2017) used the social vulnerability definition formula by considering the exposure, susceptibility, and lack of elasticity variables $[17,47]$. The results obtained were in agreement with the requirements of the situation and together they exhibited a high rationality rate. This study uses the formula as follows: By referring to the social vulnerability calculation method in previous research, we can conclude that $Y$ is the social vulnerability value, $E$ is the value of the degree of exposure, $S$ is the value of susceptibility, and $L$ is the insufficient resilience ability. $Y$ is calculated as follows: $[17,46,47]$ :

$$
\mathrm{Y}=\mathrm{E} \times 0.5 \times(\mathrm{S}+\mathrm{L}),
$$

In the natural classification analysis method of ArcGIS 10.4, the four distribution states of exposure level, susceptibility, resilience, and social vulnerability are divided into five levels: Very low, low, medium, high, and very high. 


\section{Results}

The weight of each index obtained by the entropy method is shown in Table 2. According to the results of Table 2, three indicators, namely submersion depth, population, and submersion time, are of great importance, subsequently followed by the factors of female population, the density of evacuation facilities, and the density of medical facilities. Based on the evacuation indicators, both exposure and susceptibility turn out to be significant in terms of the social vulnerability assessment.

Table 2. The weight of each index.

\begin{tabular}{ccc}
\hline Evaluation Item & Index & Weight \\
\hline \multirow{3}{*}{ Exposure } & Population (number) & 0.1154 \\
& Submersion depth $(\mathrm{m})$ & 0.1161 \\
& Submersion time (hr) & 0.1142 \\
\hline \multirow{3}{*}{ Susceptibility } & 0 to 9 years old population (number) & 0.0175 \\
& 65 to 74 years old population (number) & 0.0841 \\
& Over 75 years old population (number) & 0.0433 \\
& Female population (number) & 0.1131 \\
& the isolated population (number) & 0.0736 \\
\hline \multirow{2}{*}{ Resilience } & Density of medical facilities (number $/ \mathrm{m}^{2}$ ) & 0.1101 \\
& Family personnel (number) & 0.1005 \\
& Density of evacuation facility(number $/ \mathrm{m}^{2}$ ) & 0.1121 \\
\hline
\end{tabular}

Figure 3 shows the distribution of exposure to flooding in the study area. This exposure level was calculated using a combination of three indicators of submersion levels, including: Depth, submersion time, and population. Figure 3a shows the submersion depth distribution. Notably, the depth areas between $3.7 \mathrm{~m}$ and $4.4 \mathrm{~m}$ were the dominant ones, accounting for $22.8 \%$ of the total area, which was primarily distributed in the northwest. Additionally, the depth areas between $1.2 \mathrm{~m}$ and $2.3 \mathrm{~m}$, which accounts for $22.7 \%$ of the total area, were located in the east region of the study area. Figure $3 \mathrm{~b}$ presents the submersion duration distribution map. The duration hours between 133 and $546 \mathrm{~h}$, accounting for $36.7 \%$ of the total area, and located in the southwest region of the study area, can be examined. Figure $3 \mathrm{c}$ shows the population distribution map. A population of 40,312 was submerged, accounting for $89 \%$ of the total population. Finally, the exposure map is shown in Figure 3d. We found very high exposure levels in the southwest that changed gradually to very low exposure in the northeast of the study area.

Figure 4 shows the distribution of susceptibility in the study area. Five indices are used to measure this distribution: Population of 0-9 years old, the population of 65-74 years old, the population of over 75 years old, the female population, and the isolated population. The distribution diagrams for each indicator are shown in Figure 4a-e, respectively. As shown in Figure 4f, the susceptibility is classified as very low, low, medium, high, and very high, and their proportions in the total area are $13 \%, 25 \%, 24 \%, 29 \%$, and $9 \%$, respectively. It is worth noting that the more susceptible areas are located in the western region of Katsushika Ward, because the population of 65 to 74 years old, the female population, and the isolated population are distributed primarily in the western region. The results also indicate that the northeast of Katsushika Ward is situated in the lowest susceptibility area. 

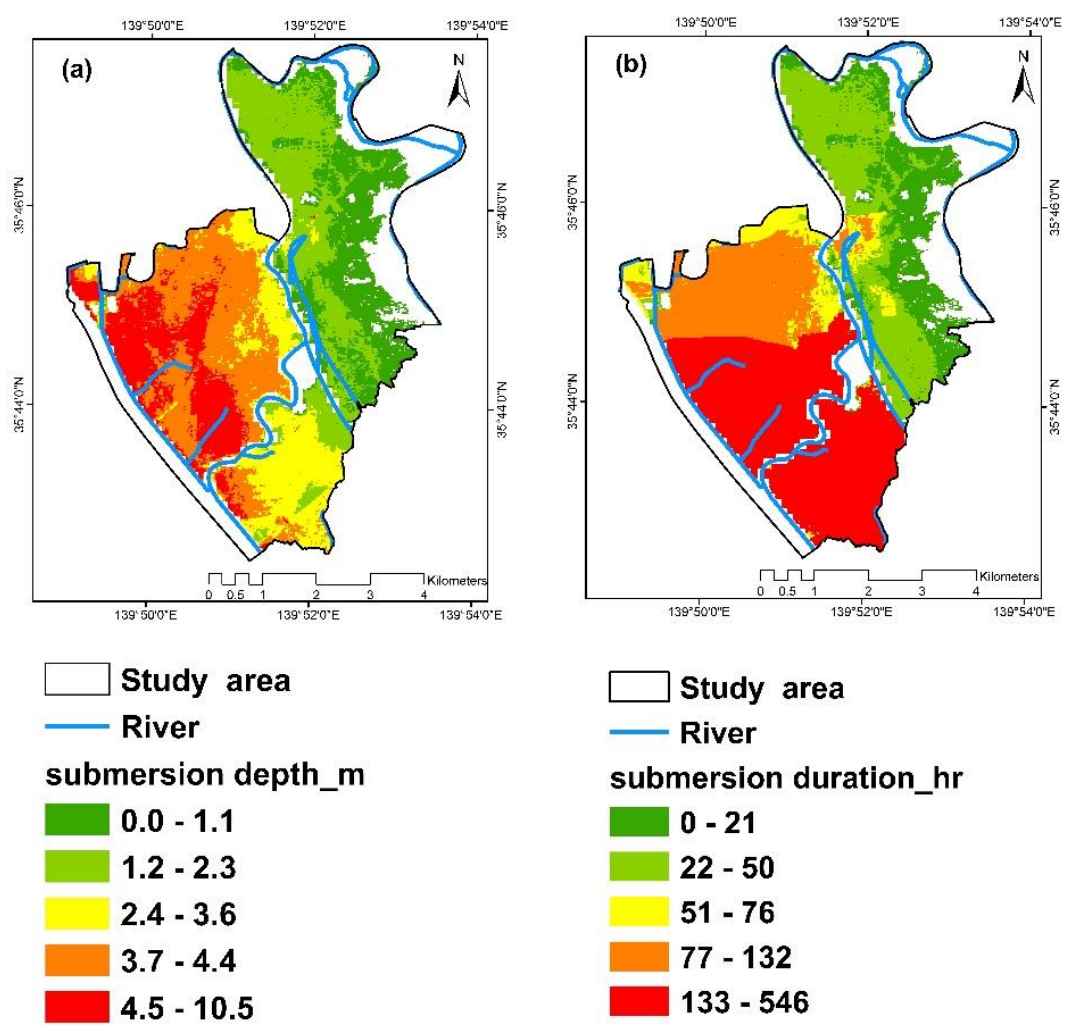

submersion duration_hr
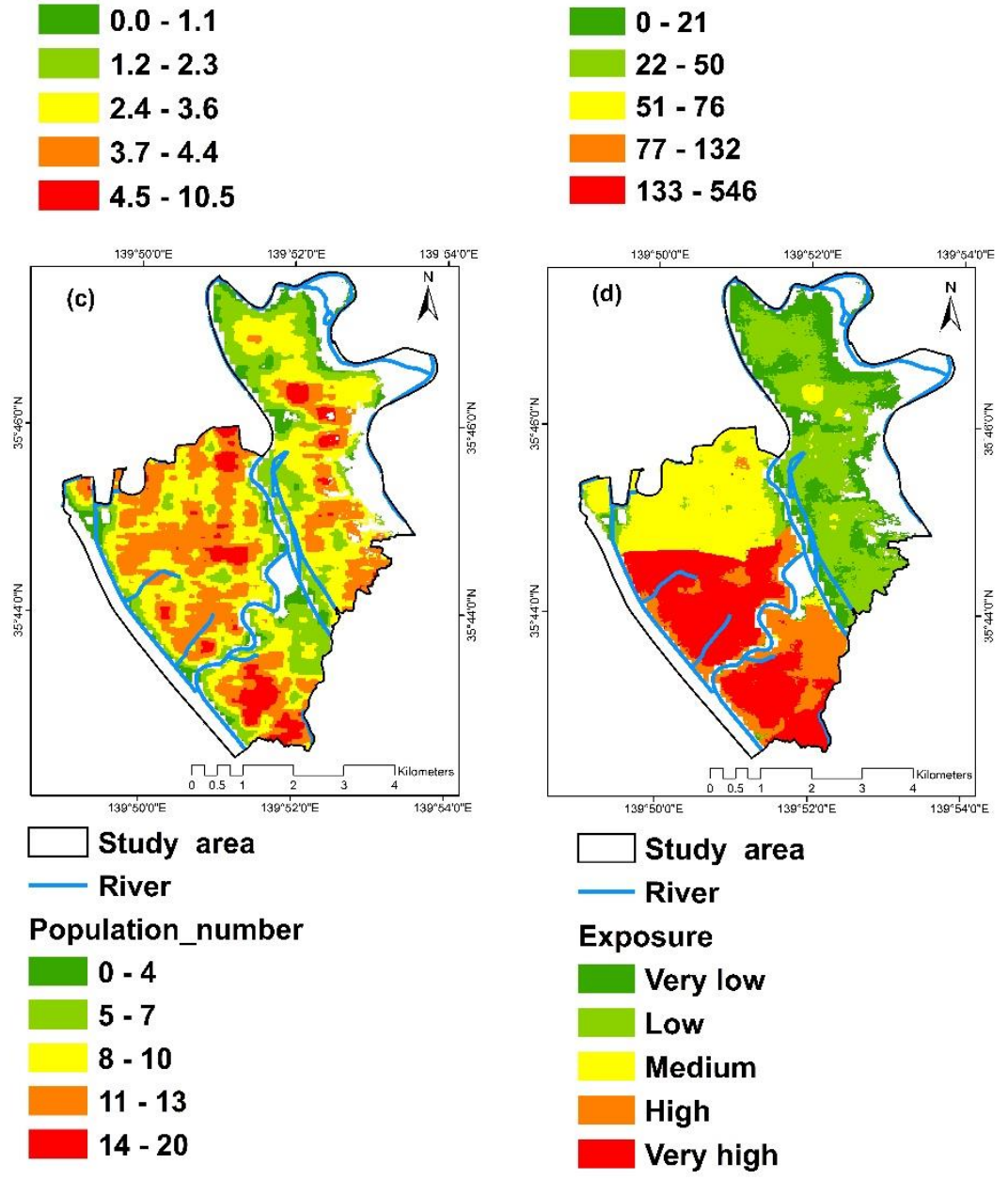

Figure 3. Exposure to flood: (a) Submersion depth distribution; (b) submersion duration distribution; (c) population distribution; (d) exposure. 

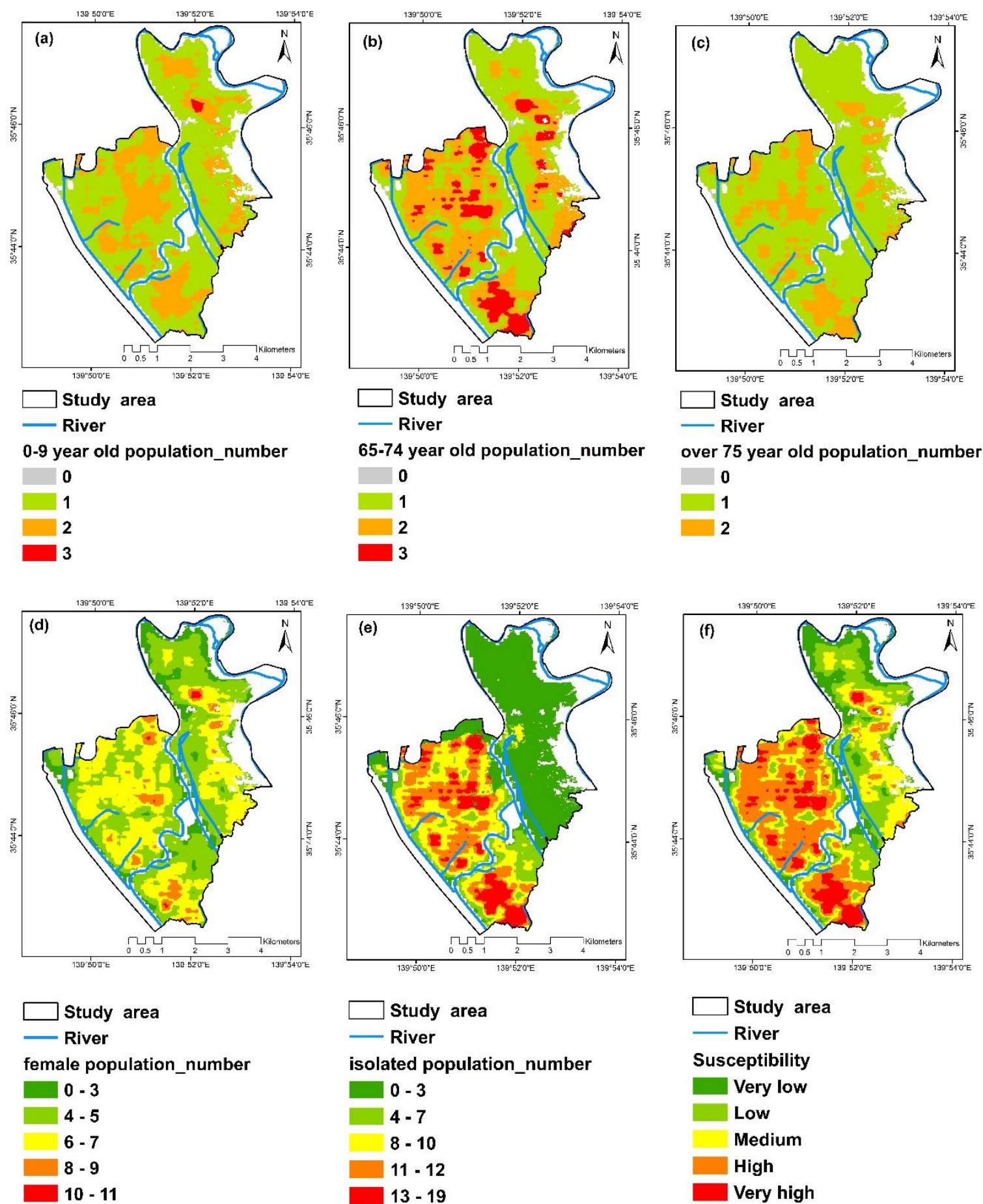

Figure 4. Susceptibility to flooding: (a) 0-9 years old population distribution; (b) 65-74 years old population distribution; (c) over 75 years old population distribution; (d) female population distribution; (e) the isolated population distribution; (f) susceptibility.

The resilience in the study area is shown in Figure 5, which is a combination of three indicators: The number of family personnel, the density of refuge facilities, and the density of medical facilities. The distribution maps for each indicator are shown in Figure 5a-c. As shown in Figure 5d, the resilience measurement is classified as five parts: Very low, low, medium, high, and very high. The number of family personnel, evacuation facilities, and medical facilities is separately concentrated in the southwestern area, the northwest and northeastern areas, and in the vicinity of the southwestern, northeast, and northwest parts of the region, respectively. The resilience distribution maps clearly 
show that the "very high", "high and medium", "low", and "very low" are mainly distributed in the southeastern, northwestern, and eastern regions and near the river, respectively. The results also indicate that the northeast of Katsushika ward is situated in the lowest resilience area. Resilience in some southeastern regions is extremely low. In addition, the density of medical and evacuation facilities in the peripheral Katsushika ward is relatively low, because the density of facilities was calculated merely within the boundary of this area.
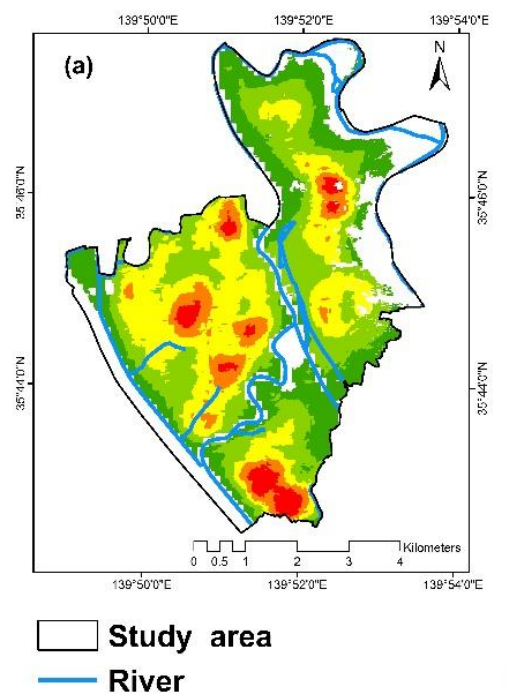

Family personnel_person
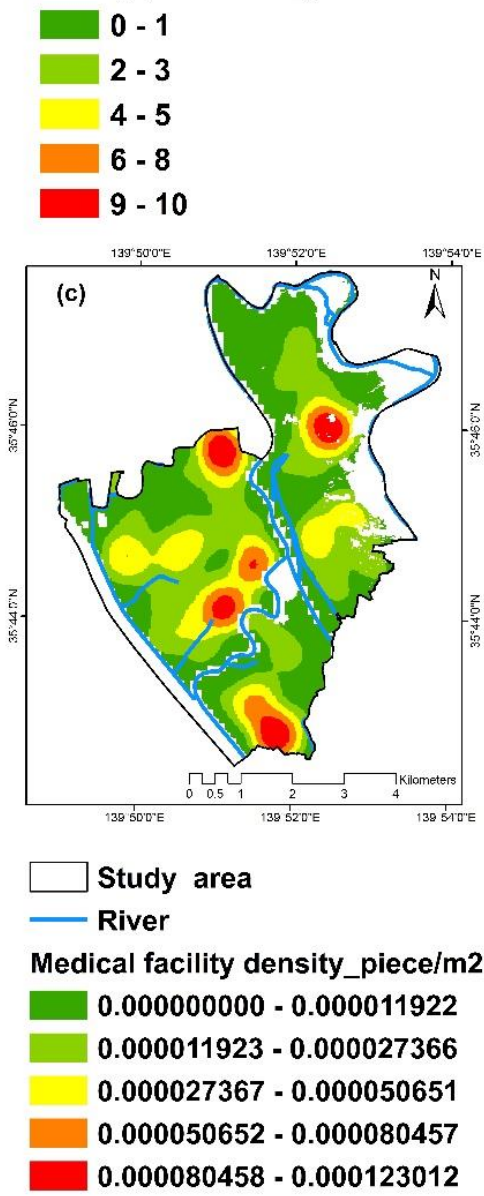

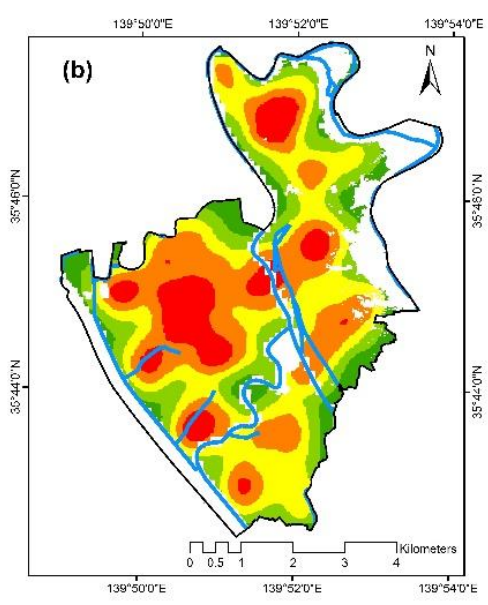

Study area River

Evacuation facility density_piece/m2

$0.0000000-0.0000018$

$0.0000020-0.0000033$

$0.0000035-0.0000046$

$0.0000048-0.0000058$

$0.0000059-0.0000076$

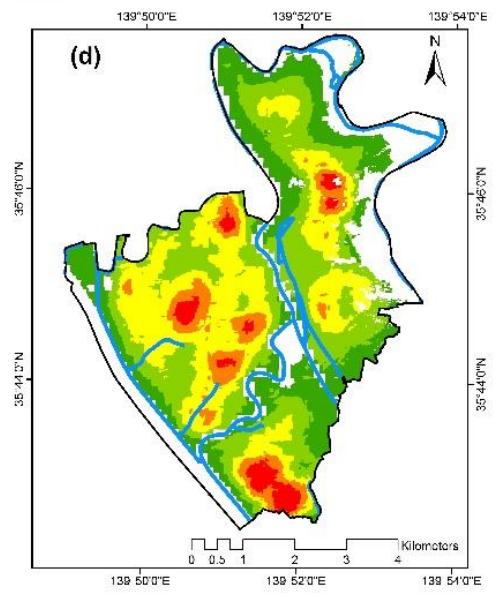

Study area

River

Resilience

Very low

Low

Medium

High

Very high

Figure 5. Resilience to flood: (a) Family personnel distribution; (b) evacuation facility density; (c) medical facility density; (d) resilience. 
Figure 6 shows the distribution of social vulnerability in the study area. It is the result of a combination of three evaluation items, including the: Degree of exposure, susceptibility, and resilience. The distribution of social vulnerability is divided into five levels, including: Very low, low, medium, high, and extremely high. "High" and "very high" levels are distributed widely in the southwestern part. The moderate levels are distributed widely in the northwestern part. "Low" levels are distributed widely in the eastern part. Although the "very low" level grids are distributed widely, the area of "high" and "very high" levels occupies $36 \%$ of the area.

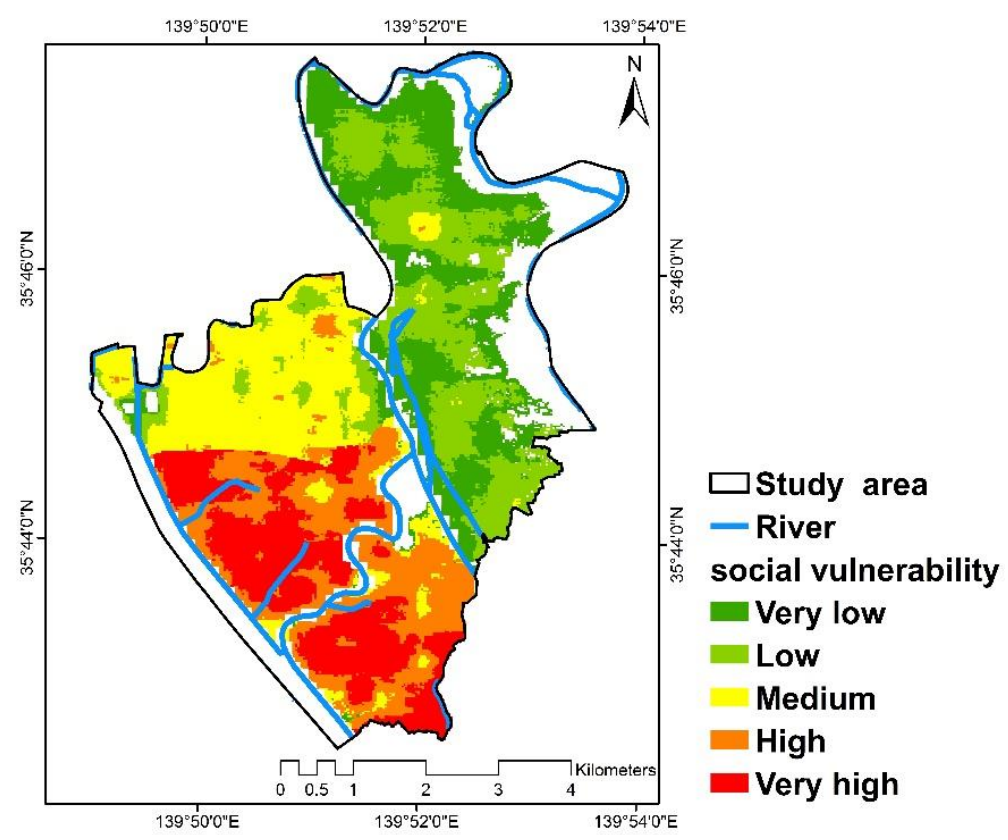

Figure 6. The distribution of social vulnerability to flood.

\section{Discussion}

We found that the indicators from the depth and duration of immersion are of great significance under the exposure analysis. The western region is more at risk than the eastern one. From the perspective of immersion depth, the northwestern region is more at risk than the southwestern one. However, from the viewpoint of flood duration, the southwestern region is more at risk than the northwest. In terms of population distribution, the population in the northwestern region is more distributed, but the population in the southwestern region is more concentrated. Therefore, the focus of flood prevention measures need to be different in the southwestern and northwestern regions. Both regions should pay more attention to warnings and safe transfers at the earliest risk stage. Also, the northwestern region should focus on emergency shelter, while the southwestern region should place more emphasis on long-term evacuation and rescue. In the flood of 1947, 54,128 houses were flooded, and the Katsushika area was immersed for 20 days. The victim count reached 218,251. Ships were used for rescue and food distribution. Its occurrence, which occurred in the second year after the end of World War II, made social and economic life more unstable. From past experience, it is evident that expanding personnel and material resources are of paramount importance.

We found that the distribution of the five indicators is more prominent in the western than in the eastern region. Therefore, the western region should pay more attention to the evacuation and rescue of vulnerable people. When it comes to the susceptibility analysis, we also realized and emphasized the importance of two indicators from isolated people and people in the age range of 65-74, whose early warning and transfer are indispensable for their safety. On the other hand, the indicator from the female group would be plausibly important due to its large population. Next, the order of rescue must be seriously considered for the population over 75 years old, 65-74 years old, and 0-9 years old. The isolated populations of these groups are at greatest risk, and immediate action should be taken. In the 
large-scale evacuation study of floods in the National Survey of Year 2015, the risk of flooding in in the Katsushika Ward was high, and the submersion time was more than three days $[59,60]$. Owing to the large water immersion area, the areas with depths of $1.2 \mathrm{~m}$ or more accounts for more than $80 \%$ of the total immersed area. When this occurs, it is especially difficult for children and the elderly to seek refuge on their own. Areas that have been immersed for more than three days covered over half of the total area, resulting in many isolated populations.

According to the resilience analysis, although there is a greater number of family members in the southwestern region, the problems are primarily focused on the difficulty of evacuation due to limited evacuation facilities. Despite the high density of medical facilities, the depth of immersion in the area is between $2.4-10.5 \mathrm{~m}$. Thus, the medical facilities may also be prone to flooding, potentially resulting in the temporary suspension of medical services. Because the flooding period is $133-546 \mathrm{~h}$, long-term flooding will cause problems, such as the spread of infectious diseases owing to insufficient medical care. During the floods of 1947, the southwestern region encountered difficulties in evacuation and the medical facilities were paralyzed by flooding, causing a spread of infections, owing to inadequate medical emergency services. This flood caused a significant loss of life and property. Recovery after a disaster generally takes a long time. Therefore, the southwestern region should focus on the establishment of emergency evacuation facilities, the corresponding capabilities of medical facilities, and the prevention of post-disaster infections.

In terms of the results in this study, the distribution of social vulnerability in the Katsushika area is different from the distribution of flood risk shown in previous research [61]. In the study, the author concluded that the northwestern region of north Nakagawa in the Katsushika area is at relatively high risk, while the southwestern region is less dangerous than the eastern region. These results are different from the results of this study. This difference is because reference [61] had a different setting of the flood model and did not consider the duration of the flooding. Even if there are reports on vulnerability analysis in the Tokyo area, they did not focus on floods, and their vulnerability analyses were on a relatively large scale [62]. In terms of regions, according to the flood disaster map of Katsushika region, the local government is developing measures to reduce social vulnerability by using this information [63]. The risk level in the flood disaster map of the Arakawa in the Katsushika area is ordered as follows: Eastern region $<$ southwest region $<$ northwest region. The government can develop measures to reduce social vulnerability by using this information. However, the situations between the north parts of the Keisei line and south parts of Nakagawa region are different from the results in this study. This is because the flood disaster map of the Arakawa in the Katsushika area is only expressed by the depth of the flood. Therefore, it is not sufficient to formulate measures to reduce social vulnerability based on this figure. This study used local indicators to achieve the spatial vulnerability representation at the district level. The classification of indicators also helped to differentiate spatially vulnerable sub-districts to floods. The number of vulnerable people was divided into the population of the $0-9,65-75$, and $75+$ and more age ranges.

Compared with the previous research, the differentiation among the vulnerable populations will become more detailed and specific, which is useful for targeting corresponding priorities when disasters take place [37]. Based on our analysis of social vulnerability, we found that social vulnerability is related primarily to the exposure rate and susceptibility. This is similar to the results of previous studies [17]. Although the social vulnerability in "low" and "extremely low" levels is broadly distributed in this region, they are mainly localized in relatively safe eastern regions. However, social vulnerability at "high" and "extremely high" levels is concentrated in the relatively dangerous southeastern regions. Therefore, the wide distribution does not indicate that the social vulnerability to floods is low in this area. In other words, the social vulnerability of the region is significant and is primarily divided into three regions: The eastern, northwest, and southwest regions. Policies and measures to reduce the risk of flooding should be established for each of the three regions. More detailed policies and measures should be established to reduce the risk of flooding in places with high social vulnerability in the southwest region. 
We should enhance the awareness of disaster prevention in the residents of the western part of the region and strengthen propaganda methods for disaster prevention awareness. The region has not experienced large-scale floods for 70 years, and its awareness of disaster prevention is low. Also, strengthening the ward's ability to construct refugee facilities so early warnings can be established is paramount. Given the results from this study, it was found that two characteristics of "high degree of exposure" and "high susceptibility," were considerably responsible for the vulnerability in the southwest regions of the Katsushika ward. Our results also include long durations of water immersion, as well as relatively large distributions of females, isolated populations, and people aged between 65-74. When it comes to the northwestern region, its vulnerability has been mainly influenced by the degree of exposure, susceptibility, and corresponding ability in Katsushika ward. This particular region features deep immersion, large populations involved in immersion and isolation, and lacks refuge facilities. The government is now carrying out parks construction in the southwestern region to increase its foundation to $6 \mathrm{~m}$, which could be useful for rescue and refuge. However, such construction has not yet been extended to the northwestern region, even though it is also necessary [64]. The vulnerability in the eastern region, in comparison, is relatively low, yet we found that the number of family members and the density of medical facilities are also relatively low. The construction of emergency shelter facilities should be strengthened to cope with unexpected large numbers of asylum seekers. Owing to the distinctive features of these three regions, the authors believe that such information can provide the guidelines to enact the flood-tackling strategies that are more suitable for the corresponding region. In other words, this study indicates that the evaluation criteria for measuring regional vulnerability may be discussed through the accurate analysis of the quality, quantity, and distribution of social vulnerability.

According to the indicators analysis, the depth and duration of flooding have a great impact on social vulnerability. To address these issues, protection facilities and early warnings for flooding in western regions should be enhanced to cope with prolonged flooding. Secondly, in order to weaken the vulnerability to flooding among the female population, it is necessary to strengthen their awareness of flooding protection in the western region and to enable even distribution of daily supplies after disasters. In terms of refuge and medical facilities, it is essential to enhance the construction of refuge facilities in the southwestern region and to optimize the layout of medical facilities in the northwestern and southeastern regions. For family members, it is of great importance to improve the acceptability for flooding protection information in the northwestern region and to expand social activities within the region. Regarding children and senior citizens, it is necessary to sustain the propaganda distributing information on asylum knowledge and evacuation capabilities, particularly in the areas with flooding depths of $1 \mathrm{~m}$ or more. Simultaneously, flood-prevention training should be regularly conducted. For example, primary and secondary schools and welfare institutions can help carry out public outreach for refuge knowledge and flood prevention information. In terms of isolated populations, it is necessary to increase accessible refuge facilities in the northwest region, as well as to improve the capacity for materials' storage and rescue. Moreover, it is also meaningful to expand emergency shelters by connecting to private facilities, to increase the storage of lifeboats, and to organize more self-rescue trainings.

\section{Conclusions}

In this study, the index system was used to evaluate the social vulnerability to floods and analyze the social vulnerability of flooding in the Katsushika Ward, Tokyo, Japan using the information entropy method and GIS, with reference to the MOVE framework. Consequently, the following three points were identified:

(1) The analysis was performed in three different aspects: The degree of exposure to social vulnerability, susceptibility, and resilience. The index system was constructed with 11 indicators: Floating depths, flood duration, population, 0 to 9 years old population, 65 to 74 years old population, over 75 years old population, female population, isolated population, medical facility 
density, evacuation facility density, and number of households. The numbers were subsequently used to analyze the information entropy method and GIS, and the spatial distribution of the social vulnerability of floods in the Tokyo Katsushika Ward was visualized.

(2) From the perspective of social vulnerability, the western region of the Katsushika Ward was found to be at greater risk than the eastern region. In addition, the situation in the southwestern region was more dangerous than that in the northwestern region, and the distribution contained certain commonalities and heterogeneities. The general measures for flood protection were not considered based on large areas and heterogeneity.

(3) It is necessary to evaluate and analyze the social vulnerability to floods based on the characteristics of an area. Social vulnerability is related primarily to the exposure rate and susceptibility. It is extremely difficult to reduce social vulnerability when flood prevention measures to reduce exposure are insufficient. Only after improving the flood prevention measures can social vulnerability be reduced. It is necessary to focus on vulnerable people in the analysis from the point of view of susceptibility and to address their challenges.

The MOVE framework realizes the objective selection for the main indicators of social vulnerability, and the information entropy method can help scientifically determine the weight of each evaluation index to avoid interference from human factors during the weight assignment. This effectively improves the credibility of the results from social vulnerability assessments, thereby providing better services to the government to reduce social vulnerability and establish appropriate mitigation plans.

Author Contributions: The corresponding author, The corresponding author proposed the topic and spearheaded the data processing and analysis, as well as the writing of the manuscript. T.M. helped in the design, research implementation, analysis, and writing of the manuscript.

Funding: This research received no external funding.

Conflicts of Interest: The authors declare no conflict of interest.

\section{References}

1. IPCC. Climate Change 2014: Impacts, Adaptation and Vulnerability. Contribution of Working Group 2 to the Fifth Assessment Report of the Intergovernmental Panel on Climate Change; Barros, V.R., Field, D.J., Dokken, M.D., Mastrandrea, K.J., Mach, T.E., Eds.; Cambridge University Press: Cambridge, UK; New York, NY, USA, 2014.

2. Miwa, A.; Yuki, Y. Construction and consideration of social disaster vulnerability index based on living style of elderly people, From the analysis for all the houses in Kita Ward; Osaka city. Trust Soc. 2013, 1, 1-22.

3. IPCC. Global Warming of $1.5^{\circ}$ C. Summary for Policy Makers; IPCC: Geneva, Switzerland, 2018.

4. Wisner, B.P.; Blaikie, P.M. At Risk: Natural Hazards, People's Vulnerability and Disasters, 2nd ed.; Routledge: London, UK, 2004.

5. Clark, E.; Moser, S.C. Assessing the vulnerability of coastal communities to extreme storms, the case of Revere. Mitig. Adapt. Strateg. Glob. Chang. 1998, 3, 59-82. [CrossRef]

6. Adger, W.N. Vulnerability. Glob. Environ. Chang. 2006, 16, 268-281. [CrossRef]

7. Borg, R.P.; Indirli, M. The ANDROID case study; Venice and its territory: Vulnerability and resilience in multi-hazard scenarios. Proced. Econ. Financ. 2014, 18, 825-836. [CrossRef]

8. Fernandez, P.; Mourato, S. Social vulnerability assessment of flood risk using GIS-based multicriteria decision analysis. A case study of Vila Nova de Gaia (Portugal). Nat. Hazards Risk 2016, 7, 1367-1389. [CrossRef]

9. He, Y.; Huang, X. Assessment and influencing factors of social vulnerability to rapid urbanization in urban fringe, A case study of Xi'an. Acta Geogr. Sin. 2016, 71, 1315-1328.

10. Younus, M.; Kabir, M. Climate change vulnerability assessment and adaptation of bangladesh: Mechanisms, Notions and Solutions. Sustainability 2018, 10, 4286. [CrossRef]

11. Zhou, L. From natural vulnerability to social vulnerability, Paradigm shift in disaster research. Thinking 2012, 2,11-15.

12. Rygel, L.; O'sullivan, D.A. Method for Constructing a Social Vulnerability Index; An Application to Hurricane Storm Surges in a Developed Country. Mitig. Adapt. Strateg. Glob. Chang. 2006, 11, 741-764. [CrossRef] 
13. Rahman, M.A. Social Vulnerability to Flood: An Integrated Spatial Assessment in the United States; Association of American Geographers: Washington, DC, USA, 2018.

14. Bogaidi, J.J.; Birkmann, J. Vulnerability assessment: The first step towards sustainable risk reduction. In Disasters and Society: From Hazard Assessment to Risk Reduction; Logos Verlag Berlin: Berlin, Germany, 2004; pp. 1-83.

15. Mavhura, E.; Manyena, B. An approach for measuring social vulnerability in context: The case of flood hazards in Muzarabani district, Zimbabwe. Geoforum 2017, 86, 103-117. [CrossRef]

16. Foster, G.; Williamson, J. A review of current literature on the impact of HIV/AIDS on children in sub-Saharan Africa. Acquir. Immune Defic. Syndr. 2000, 14, S275-S284.

17. Kablan, M.K.; Dongo, K. Assessment of social vulnerability to flood in urban Côte d'Ivoire using the MOVE framework. Water 2017, 9, 292. [CrossRef]

18. Abson, D.J.; Dougill, A.J. Using principal component analysis for information-rich socio-ecological vulnerability mapping in Southern Africa. Appl. Geogr. 2012, 35, 515-524. [CrossRef]

19. de Sherbinin, A.; Bardy, G. Social vulnerability to floods in two coastal megacities, New York City and Mumbai. Vienna Yearb. Popul. Res. 2015, 13, 131-165. [CrossRef]

20. Rufat, S.; Tate, E. Social vulnerability to floods: Review of case studies and implications for measurement. Int. J. Disaster Risk Reduct. 2015, 14, 470-486. [CrossRef]

21. Turner, B.L.; Kasperson, R.E. A framework for vulnerability analysis in sustainability science. Proc. Natl. Acad. Sci. USA 2003, 100, 8074-8079. [CrossRef]

22. Cutter, S.L. Vulnerability to environmental hazards. Prog. Hum. Geogr. 1996, 20, 529-539. [CrossRef]

23. Parker, D.; Tapsell, S. Deliverable 2.1. Relations between different types of social and economic vulnerability. Final draft report submitted to EU project 'Enhancing resilience of communities and territories facing natural and na-tech hazards'. 2009. Available online: https://www.researchgate.net/publication/264474096_ Relations_between_different_types_of_social_and_economic_vulnerability (accessed on 5 December 2018).

24. Cutter, S.L. The vulnerability of science and the science of vulnerability. Ann. Assoc. Am. Geogr. 2003, 3, 1-12. [CrossRef]

25. Turner, B.L.; Matsond, P.A. Illustrating the coupled human-environment system for vulnerability analysis, three case studies. Proc. Natl. Acad. Sci. USA 2003, 100, 8080-8085. [CrossRef]

26. Birkmann, J.; Cardona, O.D. Framing vulnerability, risk and societal responses, the MOVE framework. Nat. Hazards 2013, 67, 193-211. [CrossRef]

27. Mustafa, D. Structural causes of vulnerability to flood hazard in Pakistan. Econ. Geogr. 1998, 74, $289-305$. [CrossRef]

28. Gaillard, J.C.; Liamzon, C.C. Natural disaster, a retrospect into the causes of the late- 2004 typhoon disaster in Eastern Luzon, Philippines. Environ. Hazards 2007, 7, 257-270. [CrossRef]

29. Younus, M. An assessment of vulnerability and adaptation to cyclones through impact assessment guidelines: A bottom-up case study from Bangladesh coast. Nat. Hazards 2017, 89, 1437-1459. [CrossRef]

30. Birkmann, J. Measuring vulnerability to promote disaster-resilient societies: Conceptual frameworks and definitions. In Measuring Vulnerability to Natural Hazards: Towards Disaster Resilient Societies; United Nations University Press: Tokyo, Japan, 2006.

31. Ge, Y.; Shi, P.J. Improvement and application of vulnerability assessment methodology for flood hazards in China: Using Changsha Prefecture as a case study. J. Nat. Disaster 2005, 14, 54-58.

32. Wu, J.; Chiang, Y. The development and analysis on natural disaster statistics index system in Taiwan. J. Geogr. Sci. 2008, 51, 65-84.

33. Chen, L.; Xu, W.; Zhou, X.; Ma, Y.; Yuan, Y.; Qian, X.; Ge, Y. The research on social vulnerability assessment of natural disasters: Taking Shanghai as an example. J. Catastrophol. 2012, 27, 98-100.

34. Uchiyama, K. The spatial distribution of social vulnerability to environmental hazards, A case study of Kobe City at the Great Hanshin-Awaji Earthquake. Collect. Assoc. Jpn. Geogr. Tsukuba. Japan. 2017.

35. Anderson, B.L.; King, D. Mitigation of the impact of tropical cyclones in northern Australia through community capacity enhancement. Mitig. Adapt. Strateg. Glob. Chang. 2005, 10, 367-392. [CrossRef]

36. Wang, L.; Liao, X. The Social vulnerability of urban flooding disaster in Hsinchu city. J. Eng. Environ. 2018, $38,94-113$.

37. Tetsuya, O. The current status and future perspectives of flood risk management. JICE Rep. Rep. Jpn. Inst. Constr. Eng. 2017, 31, 2-7. 
38. Cannon, T. Gender and climate hazards in Bangladesh. Gender Dev. 2002, 10, 45-50. [CrossRef]

39. Ikeda, K. Gender Differences in Human Loss and Vulnerability in Natural Disasters, A Case Study from Bangladesh. Indian J. Gender Stud. 1995, 2, 171-193. [CrossRef]

40. Snith, K. Environmental Hazards: Assessing Risk and Reducing Disaster; Routledge: London, UK, 2003.

41. Asaka, M.; Shigeo, T. A confirmatory study on the influence of questionnaire seismic intensity and social vulnerability in Kobe city of the Great Hanshin-Awaji Earthquake on building damage and direct death number. J. Reg. Saf. 2009, 11, 89-96.

42. Fatemi, F.; Ardalan, A. Social vulnerability indicators in disasters, Findings from a systematic review. Int. J. Disaster Risk Reduct. 2017, 22, 219-227. [CrossRef]

43. Kundzewicz, Z.W.; Kanae, S. Flood risk and climate change, global and regional perspectives. Hydrol. Sci. J. 2014, 59, 1-28. [CrossRef]

44. Lin, W. Empirical Analyzing the Relationship between Direct Economic Damage Caused by Natural Disasters and Economic and Social Factors, toward to Improve Safety and Security. Econ. Rev. Kyoto Univ. 2015, 188, 79-91.

45. Sané, O.D.; Gaye, A.T. Social vulnerability assessment to flood in Medina Gounass Dakar. J. Geogr. Inf. Syst. 2015, 7, 415-429. [CrossRef]

46. Welle, T.; Depietri, Y.; Angignard, M.; Birkmann, J.; Renaud, F.; Greiving, S. Vulnerability assessment to heat waves, floods, and earthquakes using the MOVE framework, Test Case Cologne, Germany. Assess. Vulnerabil. Nat. Hazards 2014, 91-124. [CrossRef]

47. Depietri., Y.; Welle, T. Social vulnerability assessment of the Cologne urban area (Germany) to heat waves, links to ecosystem services. Int. J. Disaster Risk Reduct. 2013, 6, 98-117. [CrossRef]

48. Hagenlocher, M.; Delmelle, E. Assessing socioeconomic vulnerability to dengue fever in Cali, Colombia: Statistical vs expert-based modeling. Int. J. Health Geogr. 2013, 12, 36-50. [CrossRef]

49. Bizimana, J.P.; Twarabamenye, E.; Kienberger, S. Assessing the social vulnerability to malaria in Rwanda. Malar. J. 2015, 14, 2-523. [CrossRef] [PubMed]

50. Williams, H.T.; Muhammed, B.U. Modelling Social Vulnerability to Malaria Risk in Katsina-Ala Local Government Area, floods, Benue State Nigeria. J. Geogr. Environ. Earth Sci. Int. 2018, 14, $2454-57352$.

51. Fekete, A. Assessment of Social Vulnerability River Floods in Germany; United Nations University, Institute for Environment and Human Security: Tokyo, Japan, 2010.

52. Atsuyuki, S.; Jiang, Y. The national census is calculated by using the population of any regions. Aichi Univ. Inf. Media Cent. Bull. 2015, 25, 1-15.

53. The United Nations Office for Disaster Risk Reduction. Terminology on Disaster Risk Reduction; The United Nations Office for Disaster Risk Reduction: Geneva, Switzerland, 2009.

54. Daniels, R.J. On Risk and Disaster, Lessons from Hurricane Katrina; University of Pennsylvania Press: Philadelphia, PA, USA, 2006.

55. Jain, Y.K.; Bhandara, S.K. Min max normalization based data perturbation method for privacy protection. Int. J. Comput. Commun. Technol. 2011, 2, 45-50.

56. Shannon, C. A Mathematical Theory of Communication. Bell Syst. Tech. J. 1948, 27, 379-423. [CrossRef]

57. Zhang, X. Entropy weight theory based integrated evaluation model of natural disasters. J. Nat. Disasters 2009, 18, 190-192.

58. He, Q. Estimating the Reliability of Composite Scores; Office of the Examinations and Qualifications Regulator (Ofqual): Coventry, England, 2009.

59. Yukawa, S.; Hatayama, M. A Study on flood evacuation in congested areas using network equilibrium model. Presented at Research Meeting on Civil Engineering Planning, Yamanashi, Japan, 21 November 2010.

60. Tetsuya, O. A Study on the vulnerability assessment of inundation areas in the event of a large-scale flood in the Tokyo metropolitan area. Adv. River Eng. (under review). 2010.

61. Takanashi, T. The hazard assessment and classification of Tokyo low-lying area during flood damage, Bulletin of graduate studies, Science and engineering. Chuo Univ. 2016, 46. Available online: http:/ /ir.c.chuo-u.ac.jp/ repository/search/binary/p/8813/s/7068/ (accessed on 5 December 2018).

62. The National Resilience Promotion. Result of Vulnerability Assessment. 2018. Available online: https: / / www.cas.go.jp/jp/seisaku/kokudo_kyoujinka/hyouka.html (accessed on 5 December 2018). 
63. Katsushika City Official. Katsushika City Arakawa Flood Disaster Map. 2017. Available online: http: / /www.city.katsushika.lg.jp/kurashi/1000063/1004031/1004779.html (accessed on 5 December 2018).

64. Akagi, A. The water disaster prevention initiatives in Katsushika area. River Front. 2017, 86, 12-16.

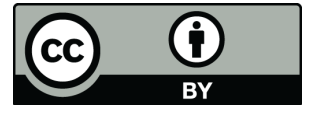

(C) 2019 by the authors. Licensee MDPI, Basel, Switzerland. This article is an open access article distributed under the terms and conditions of the Creative Commons Attribution (CC BY) license (http://creativecommons.org/licenses/by/4.0/). 